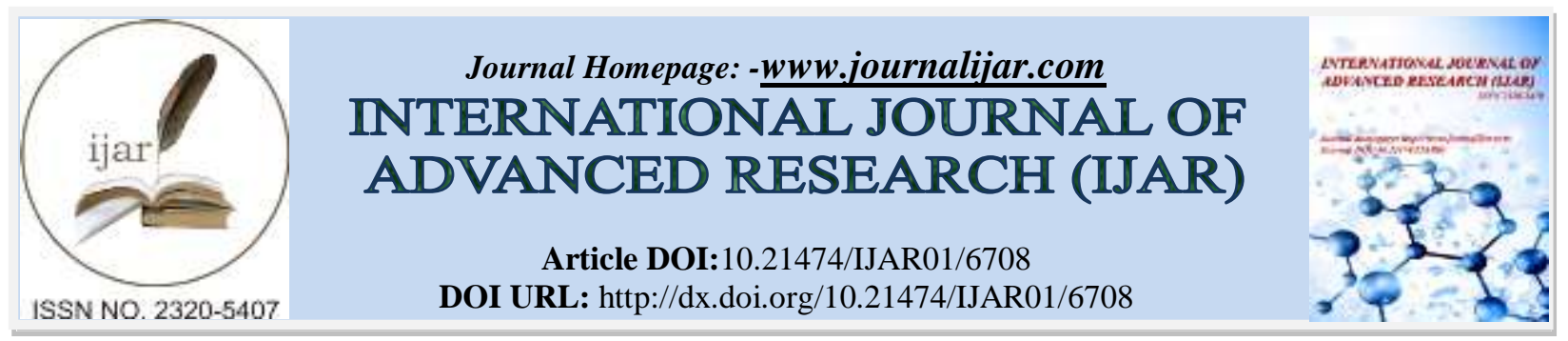

RESEARCH ARTICLE

\title{
CAUSES OF LOWER GASTROINTESTINAL TRACT BLEEDING.
}

Dr. Hazim Jabbar Aouda.

M.B. Ch.B, D.G.S, AL-Yarmouk Teaching Hospital, Baghdad, Iraq.

\section{Manuscript Info}

Manuscript History

Received: 09 January 2018

Final Accepted: 11 February 2018

Published: March 2018

Keywords:-

UGIT bleeding, Endoscopy, Bleeding per rectum............
Abstract

Back ground:- Bleeding per rectum is a common universal emergency in clinical practice and remain a major medical problem................. Objectives:- To diagnose the causes of bleeding per rectum

Patients \& Methods:-This is a prospective study of 100 patients referred to the gastrointestinal endoscopic unit at Al-yarmouk Teaching Hospital from July 2016 to July 2017.

Results:-Seventy patients were males $(70 \%) \& 30$ patients were females $(40 \%) \&$ male to female ratio were 2.33:1. The age ranged from 21 to 80 years, with mean age of the patients was 31 years \pm 5 years. The majority being in the $5^{\text {th }}$ decade of life constituting about 25 patient $(25 \%)$. The commonest cause of the bleeding were heamorrhoid 30 patients $(30 \%)$, and the next cause were ulcerative colitis 20 patients (20\%), followed by benign colonic adenomatouspolyp 15 patients (15\%), benign rectal adenomatous polyp 11 patients $(11 \%)$, solitary benign rectal ulcer 10 patients $(10 \%)$, colonic cancer7 patients $(7 \%)$, rectal cancer 4 patients $(4 \%)$ and infective colitis 3 patients $(3 \%)$

Conclusion:- Our study showed that the most common cause of bleeding were Haemorrhoid, ulcerative colitis, colonic benign adenomatous polyp, rectal benign adenomatous polyp, solitary rectal ulcer, colonic cancer, rectal cancer and infective colitis

\section{Introduction:-}

The bleeding from the gastrointestinal tract is classified into upper gastrointestinal tract bleeding (UGITB) and lower gastrointestinal tract bleeding (LGITB). ${ }^{\{1\}}$ UGITB is bleeding above the level of ligament of Treitz, where LGITB is bleeding below the level of ligament of Treitz. ${ }^{\{2\}}$ Ligament of Treitz is a fibromuscular band which extends from right crus of diaphragm to duodenojejunal flexure. ${ }^{\{2\}}$ Haemorrhage is a serious life threatening complication of gastrointestinal disease and it continues to present the clinician with a major challenge. ${ }^{\{3\}}$ flexible endoscopy has largely replaced other method of diagnosis of bleeding. ${ }^{\{4\}}$ LGIB accounts for $30-40 \%$ of all gastrointestinal bleeding and is less common than upper gastrointestinal bleeding (UGIB). ${ }^{\{5\}}$ It is estimated that UGIB accounts for 100-200 per 100,000 cases versus 20-27 per 100,000 cases for LGIB. ${ }^{\{6\}}$ Approximately $85 \%$ of lower gastrointestinal bleeding involves the colon, $10 \%$ are from bleeds that are actually upper gastrointestinal 
bleeds, and 3-5\% involve the small intestines. ${ }^{\{7\}}$ Acute bleeding is defined as bleeding of $<3$ days' duration, resulting in instability of vital signs, anaemia, and / or the need for blood transfusion. ${ }^{\{8\}}$ Chronic bleeding is defined as slow blood loss over a period of several days or longer, presenting with symptoms of occult faecal blood, intermittent melaena or scant hematochezia. ${ }^{\{8\}}$ LGIB is usually chronic and the bleeding usually ceases spontaneously $(80 \%) .{ }^{\{8\}}$ Although LGIB can occur at any age, specific disease processes are distinctive for different age groups and familiarity with this can help tailor the diagnostic workup ${ }^{\{9,10\}}$....

\section{Patients \& Methods:-}

This is a prospective study of 100 patients referred to the gastrointestinal endoscopic unit at Al-yarmouk Teaching Hospital from July 2016 to July 2017. All patients were evaluated for age,sex,present and past symptoms , history of peptic ulcer disease, dyspepsia, history of cigarette smoking, alcohol consumption ,steroid, aspirin and non steroidal anti inflammatory drugs ingestion, anticoagulant drugs taken, liver disease ,previous bleeding per rectum , previous endoscopical examination, previous surgery. Colonoscopy had been done for all patients within 48 hours of bleeding. All patients were subjected to mechanical preperation before examination which is carried out as an out patient procedure except those who need admission or those already admitted .The endoscopy was done under intravenous diazepam 10mg, During endoscopic examination a full survey of the anal canal, rectum,sigmoid colon, descending, transverse, ascending colon and caecum were done\& biopsy was taken on need \& sent for histopathology.On admission all patients were treated by bed rest and stoppage of oral intake and all patients received intravenous fluid on admission mainly crystalloids, antibiotic\& sedation. Ten patients (10\%) were need fresh frozen plasma \& blood transfusion to resuscitate them from the state of shock...............................................

\section{Results:-}

Seventy patients were males $(70 \%) \& 30$ patients were females $(40 \%) \&$ male to female ratio were $2.33: 1$. The age ranged from 21 t0 80 years, with mean age of the patients was 31 years \pm 5 years. The majority being in the $5^{\text {th }}$ decade of life constituting about 25 patient (25\%). as seen in table 1.The commonest cause of bleeding were heamorrhoid 30 patients $(30 \%)$, and the next cause were ulcerative colitis 20 patients $(20 \%)$, followed by benign colonic adenomatouspolyp15 patients (15\%), benign rectal adenomatous polyp 11 patients (11\%), solitary benign rectal ulcer 10 patients $(10 \%)$, colonic cancer 7 patients $(7 \%)$, rectal cancer 4 patients (4\%) and infective colitis 3 patients $(3 \%)$ as in the table 2 .

Table 1:- Distribution of patients according to the age groups \& sex

\begin{tabular}{|l|l|l|l|l|}
\hline Age group & No. of patient & male & female & \% \\
\hline $21-30$ & 10 & 6 & 4 & $10 \%$ \\
\hline $31-40$ & 18 & 10 & 8 & $18 \%$ \\
\hline $41-50$ & 25 & 18 & 7 & $25 \%$ \\
\hline $51-60$ & 20 & 14 & 6 & $20 \%$ \\
\hline $61-70$ & 12 & 10 & 2 & $12 \%$ \\
\hline $71-80$ & 15 & 12 & 3 & $15 \%$ \\
\hline Total & $\mathbf{1 0 0}$ & $\mathbf{7 0}$ & $\mathbf{3 0}$ & $\mathbf{1 0 0 \%}$ \\
\hline
\end{tabular}

Table 2:- The causes of the bleeding per rectum

\begin{tabular}{|l|c|l|}
\hline Cause of bleeding & No.ofpatients & \% \\
\hline Haemorrhoid & 30 & $30 \%$ \\
\hline Ulcerative Colitis & 20 & $20 \%$ \\
\hline Benigncolonic adenomatous polyp & 15 & $15 \%$ \\
\hline Benign rectal adenomatous polyp & 11 & $11 \%$ \\
\hline Solitory benign rectal ulcer & 10 & $10 \%$ \\
\hline Colonic cancer & 7 & $7 \%$ \\
\hline Rectal cancer & 4 & $4 \%$ \\
\hline Infective colitis & 3 & $3 \%$ \\
\hline Total & $\mathbf{1 0 0}$ & $\mathbf{1 0 0 \%}$ \\
\hline
\end{tabular}




\section{Discussion:-}

Lower GITB is a complex clinical problem that requires disciplined and sophisticated evaluation for successful management. ${ }^{\{11\}}$ Our study showed that the common cause of LGITB were heamorrhoid and the next cause were ulcerative colitis followed by benign colonic, adenomatouspolyp, benign rectal adenomatous polyp, solitary benign rectal ulcer, colonic cancer, rectal cancer and infective colitis. while in study done by Anthony M Vernava etal showed that the most common causes of bleeding are diverticulosis, inflammatory bowel disease (ischemic\& infective colitis),colonic neoplasia, benign ano rectal disease and arteriovenous malformation. ${ }^{\{1\}}$ The introduction of fiberoptic endoscope as a major diagnostic tool was an important mile stones in the management of LGITB, it allows for more precise diagnose of the pathology causing the bleeding. Endoscopy provides also a safe , rapid and flexible method for diagnosis and evaluation of such cases, this was true of our study. So endoscopic examination showed feasible, safe, accurate and available method used, and no failure or complication was recorded in our study and there was no suggestion that endoscopic examination provoked further bleeding. And a firm diagnosis was made in all patients of our study who are examined by endoscopy.

\section{References:-}

1. Greenberger N.J. Surgical treatment of digestive disease,secondedition,Arnold,United Kingdom,1990, pp19......

2. Sriram Bhatm M.SRBS.Manual of surgery, $4^{\text {th }}$ edition,2013,Jaypee brothers medical publisher LTD, pp 1061

3. Korman M.G.Upper gastrointestinal hemorrhage, medical education(international)Ltd,1982:pp597.

4. Alfred Cuscheri,RobertJ.C,AbdoolRahemMossa.Essential surgical practice, volium 1,fourth edition,Arnold,London,2002,pp364

5. Gralnek, IM; Neeman, Z; Strate, LL (March 2017). "Acute Lower Gastrointestinal Bleeding". New England Journal of Medicine (Review). 376 (11): 1054-63. doi:10.1056/NEJMcp1603455. PMID 28296600.

6. Farrell JJ, Friedman LS (June 2001). "Gastrointestinal bleeding in the elderly". Gastroenterol. Clin. North Am. 30 (2): 377-407, viii. PMID 11432297.

7. Dutta G, Panda M (2008). "An uncommon cause of lower gastrointestinal bleeding: a case report". Cases J. 1 (1): 235. doi:10.1186/1757-1626-1-235. PMC 2577108. PMID 18851756.

8. Jang BI. Lower Gastrointestinal Bleeding: Is Urgent Colonoscopy Necessary for All Hematochezia?. Clin Endosc. 2013;46 (5): 476-479. doi:10.5946/ce.2013.46.5.476 - Free text at pubmed - Pubmed citation.

9. Raphaeli T, Menon R. Current treatment of lower gastrointestinal hemorrhage. Clin Colon Rectal Surg. $2012 ; 25$ (04): 219-27. doi:10.1055/s-0032-1329393 - Free text at pubmed - Pubmed citation.

10. Brant WE, Helms C. Fundamentals of Diagnostic Radiology. Lippincott Williams \& Wilkins. ISBN:1608319121. Read it at Google Books - Find it at Amazon

11. AnthonyE.Vernava,BethA.Morre,WaterE.Longo,Lower gastrointestinal bleeding, Disease of the colon and rectum, voliume 40, issue7,1997, PP846-858. 